\title{
The role and mechanism of CRL4 E3 ubiquitin ligase in cancer and its potential therapy implications
}

\author{
Youzhou Sang ${ }^{1,3,4}$, Fan Yan ${ }^{1,3,4}$ and Xiubao Ren R,3,4 $^{2,4}$ \\ ${ }^{1}$ Department of Immunology, Tianjin Medical University Cancer Institute and Hospital, Tianjin, China \\ ${ }^{2}$ Department of Biotherapy, Tianjin Medical University Cancer Institute and Hospital, Tianjin, China \\ ${ }^{3}$ National Clinical Research Center of Cancer, Tianjin, China \\ ${ }^{4}$ Key Laboratory of Cancer Immunology and Biotherapy, Tianjin, China \\ Correspondence to: Xiubao Ren, email: rwziyi@yahoo.com
}

Keywords: CRL4, CUL4, ubiquitination, cancer

Received: April 08, $2015 \quad$ Accepted: September 23, $2015 \quad$ Published: October 09, 2015

This is an open-access article distributed under the terms of the Creative Commons Attribution License, which permits unrestricted use, distribution, and reproduction in any medium, provided the original author and source are credited.

\section{ABSTRACT}

CRLs (Cullin-RING E3 ubiquitin ligases) are the largest E3 ligase family in eukaryotes, which ubiquitinate a wide range of substrates involved in cell cycle regulation, signal transduction, transcriptional regulation, DNA damage response, genomic integrity, tumor suppression and embryonic development. CRL4 E3 ubiquitin ligase, as one member of CRLs family, consists of a RING finger domain protein, cullin4 (CUL4) scaffold protein and DDB1-CUL4 associated substrate receptors. The CUL4 subfamily includes two members, CUL4A and CUL4B, which share extensively sequence identity and functional redundancy. Aberrant expression of CUL4 has been found in a majority of tumors. Given the significance of CUL4 in cancer, understanding its detailed aspects of pathogenesis of human malignancy would have significant value for the treatment of cancer. Here, the work provides an overview to address the role of CRL4 E3 ubiquitin ligase in cancer development and progression, and discuss the possible mechanisms of CRL4 ligase involving in many cellular processes associated with tumor. Finally, we discuss its potential value in cancer therapy.

\section{INTRODUCTION}

Ubiquitin-proteasome pathway plays a vital role in the degradation of proteins, which is mediated by the successive enzymatic reactions involving in a ubiquitinactivating enzyme (E1), a ubiquitin-conjugating enzyme (E2), and a ubiquitin ligase (E3) [1]. In this process, the ubiquitin ligase determines the substrate specificity. Among the diverse E3 enzymes, the cullin-RING ubiquitin ligases (CRLs) are the largest E3 ligase family in eukaryotes [2]. The cullin as a scaffold protein binds with its C-terminal region to a RING-finger protein $\mathrm{RBX1/ROC1}$, whereas its $\mathrm{N}$-terminus associates with a cullin-specific adaptor protein to recruit a large family of substrate receptors, each of which can target diverse substrates [3]. CRLs activity can be regulated by a process termed neddylation that involves cullin-associated protein called Nedd8 [4]. Cullin neddylation is reverted by the COP9 signalosome (CSN) through a reaction known as deneddylation [5].

The human cullin family mainly comprises of eight intimately related proteins (CUL1, CUL2, CUL3, CUL4A, CUL4B, CUL5, CUL7 and CUL9). Compared to another cullins, the CUL4 subfamily includes two members, CUL4A and CUL4B, which share over $80 \%$ sequence identity and functional redundancy. Each cullin acts as a scaffold to interact with a specific adaptor and diverse substrate receptors. For instance, the CUL1-Rbx1 complex utilizes Skp1 as its adaptor to interact with a myriad of F-box proteins that act as substrate receptors [6]. However, CUL4 uses DNA damage binding protein 1 (DDB1) as adaptor and CUL4-associated factors (DCAFs) as substrate receptors to identify a large number of substrate proteins $[2,7,8]$. That the aberrant expression of CUL4 has been founded in many types of tumors suggests the close relationship between CUL4 and cancer [9, 10], and more and more researches recently have shown that CRL4 ligase is involved in some cellular processes 
associated with tumor, such as cell cycle regulation, signal transduction, transcriptional regulation, DNA damage response, genomic integrity, tumor suppression and so on [2]. This review provides insights for the role of CUL4 ligase in cancer development and progression, and summarizes current researches on the functional regulation of CUL4 in tumor-related changes, including cell cycle, DNA damage repair, histone methylation, signaling pathways, oncoproteins turnover. Additionally, potential therapeutic value of CUL4 in cancer is also discussed in the work.

\section{CRL4 E3 UBIQUITIN LIGASE IN CANCER}

CUL4A and CUL4B share extensive homology and functional redundancy, however CUL4A has drawn much more attention as a result of a large body of evidence demonstrating its association with cancer. Recent years, accumulating studies have shown that CUL4A expresses abnormally in multiple cancers including breast cancer, squamous cell carcinoma, pleural mesothelioma [9-12], and one latest study found CUL4A overexpressed in nonsmall-cell lung cancer and stimulated the latter growth as well as tumorigenesis [13]. CUL4A overexpression contributes to tumor progression, metastasis, and poorer survival rate of cancer patients [14]. For example, Chen et al. showed that CUL4A amplified in lymph nodenegative breast cancer, and these patients with CUL4 overexpression showed shorter overall and disease-free survival (OS and DFS) [15]. And a report found that CUL4A silencing in CUL4A-overexpressing breast cancer cells induced a reduction of cell proliferation and colony formation and decreased the tumor development [16]. These results suggest CUL4A may be a critical contributor to the progression and development of breast cancer. In addition, CUL4A knockout mice are resistant to UVinduced skin carcinogenesis [17], while overexpression of CUL4A in transgenic mouse lungs induces potential hyperplasia [18]. Compared to CUL4A, reports about the relationship between CUL4B and tumor are lack. Recent researches are mainly about that CUL4B is causally associated with human $\mathrm{X}$-linked mental retardation [19]. Nevertheless, a recent work found that CUL4B overexpressed in colon cancer, and its overexpression closely related to tumor stage, histological differentiation, vascular invasion and distant metastasis. And patients with positive CUL4B expression had a lower OS and DFS rate than patients with negative CUL4B expression [20]. Meanwhile, recent studies showed that CUL4B upregulated in some other cancers such as cervix, lung, esophagus and breast cancers, which associated with tumor invasion and lymph node metastasis [21]. Furthermore, CUL4B overexpression promotes the development of spontaneous liver tumors at a high rate and enhances DEN-induced hepatocarcinogenesis in transgenic mice [22]. Consequently, based on the above facts, CRL4 E3 ligase plays a crucial role in cancer and represents an ideal target site for therapeutic intervention.

\section{THE POSSIBLE MECHANISM OF CRL4 E3 UBIQUITIN LIGASE INDUCING CANCER}

It is becoming increasingly clear that through selective degradation of target proteins, CRL4 ligases participate in multiple physiological processes such as cell cycle, nucleotide excision repair and histone methylation. Furthermore, such physiological processes have great relevance with the development of human cancer. In addition, some substrates of CRL4 are involved in many signaling pathways related to cancinogenesis and include multiple oncoproteins. (Figure 1) The detailed mechanism of CRL4 ligase regulating the above processes will be discussed below.

\section{CRL4 AND CELL CYCLE}

Based on a majority of studies, many researchers have shown that cancer can be regarded as a disease of the cell cycle. Deregulation of the cell cycle and genome instability are two common features of cancer cells [23], and various mechanisms exist to preserve the integrity of the genome and guard against cancer. In normal cells, cell cycle progression is strictly regulated by multiple mechanisms to ensure its orderly progress. Most researches consider that it is regulated mainly by the cell cycle proteins (Cyclins), cyclin-dependent kinases (CDKs) and cyclin-dependent kinase inhibitors (CDKIs). Consequently, regulation of the above proteins is crucial for cell cycle process, and more and more researches have found the expression level of these proteins was clearly associated with tumorigenesis and cancer progression. In recent years, accumulating evidence has identified that the turnovers of the above proteins are regulated by CRL4 ubiquitin ligase.

Cyclin E is a regulator of the G1 phase of the cell cycle and proper regulation of this cyclin is essential for S-phase transition and multiple processes safeguarding the accuracy of DNA replication [24]. Abnormal cyclin E expression has been found in several types of tumors. For example, altered expression of cyclin E occurs in the breast cancer and can serve as molecular marker which associates with the prognosis and therapy [25]. The overexpression of Cyclin $\mathrm{E}$ is also implicated in carcinomas at various sites along the gastrointestinal tract, especially the stomach and the colorectal region [26]. Consequently, the turnover level of cyclin E correlates with the pathogenesis of cancer. Many reports have suggested that cyclin $\mathrm{E}$ is tightly regulated by ubiquitinmediated proteolysis system. Wild-type CUL4B-RING E3 ligase enhances the degradation of cyclin E in HEK 293 cells, while down-regulation of CUL4B results in a significant cyclin $\mathrm{E}$ accumulation compared with that 
of control cells [27, 28]. Similar results are observed in HeLa cells, and RNAi of CUL4B inhibits the proliferation of HeLa cells by prolonging $\mathrm{S}$ phase progression. These results suggest that the inhibiting effect of CUL4B on cell proliferation may be mediated by targeting cyclin $\mathrm{E}$ for degradation [27]. Interestingly, silencing of CUL4A also causes an increase in cyclin E levels [28]. Thus, aberrant expression of CUL4A/B contributes to unstable cyclin E level leading to unusual cell cycle, which may induce relevant cancer.

CDK inhibitor p21 is a critical effector in response to a variety of intracellular and extracellular stress signals. p21 can inhibit the kinase activity of $\mathrm{Cdk} 2$, thereby preventing progression into or through the S phase [29]. Since it was discovered, an abundance of researches have provided insights into the role of p21 as a regulator of tumor development and progression $[30,31]$. Therefore, it will be of interest to test whether p21 downregulation resulting from the upregulation of CUL4 contributes to tumor activity. Many reports have shown that p21 accumulates during G1 phase but is degraded during $\mathrm{S}$ phase [32]. In addition, it is degraded after UV irradiation [33]. Nishitani et al. found the silence of CUL4, DDB1, CDT2 or PCNA by siRNA increased the level of p21 in $\mathrm{S}$ phase and inhibited its degradation following UV irradiation [34]. This suggests CUL4-DDB1 ${ }^{\mathrm{CDT} 2}$ degrades p21 in PCNA-dependent way. In Cul4a conditional knockout mice, p21 protein increases [17], while the turnover of p21 is stabilized in DDB1 ${ }^{-/-}$cells [35]. These results provide proof for the accumulation of $\mathrm{p} 21$ observed in $\mathrm{Cul}_{4 \mathrm{a}^{-/}}$cells. Silencing of CUL4B expression also increases p21 level in extra-embryonic cells [36] but has little effect in MEF cells [17]. Furthermore, Hall et al. found that $\mathrm{CRL} 4^{\mathrm{Cd} 2}$-mediated degradation of $\mathrm{p} 21$ was regulated by $\mathrm{C} / \mathrm{EBP} \alpha$, the bZIP transcription factor, in response to UV-induced DNA damage. Following UV exposure, Cdt2 level failed to be down-regulated in $\mathrm{C} / \mathrm{EBP} \alpha$-deficient keratinocytes, which consequently affected CRL4 to degrade p21 [37].

The turnover of p27 is tightly associated with cell cycle progression. Low expression of p27 would lead to rapid cell cycle progression and eventually induce oncogenesis. Multiple cancers have low level of p27 such as colon, prostate and ovarian tumor and so on. Moreover, downregulation of $\mathrm{p} 27$ relates to tumor patients prognosis [38]. The expression level of p27 could be modulated by CRL4 ${ }^{\text {CDT2 }}$ for degradation, and inactivation of CUL4A by siRNA is sufficient to cause the accumulation of $\mathrm{p} 27$, which results in $\mathrm{G} 1$ cell cycle arrest in treated cells [28, $39,40]$. Although many studies point that the level of p27 protein is controlled by CRL4, whether p27 is one direct substrate of CRL4 has been controversial. Consequently, further studies are needed to verify the above-mentioned question.

Additionally, Kotake et al. recently showed CUL4A could directly bind to $\mathrm{p} 16$, which was required for the latter activation [41]. And previous studies have suggested that p16 encodes a specific inhibitor of the CDK4 and CDK6, frequently mutated or inactivated in a majority of human tumors $[42,43]$. Knockdown of the

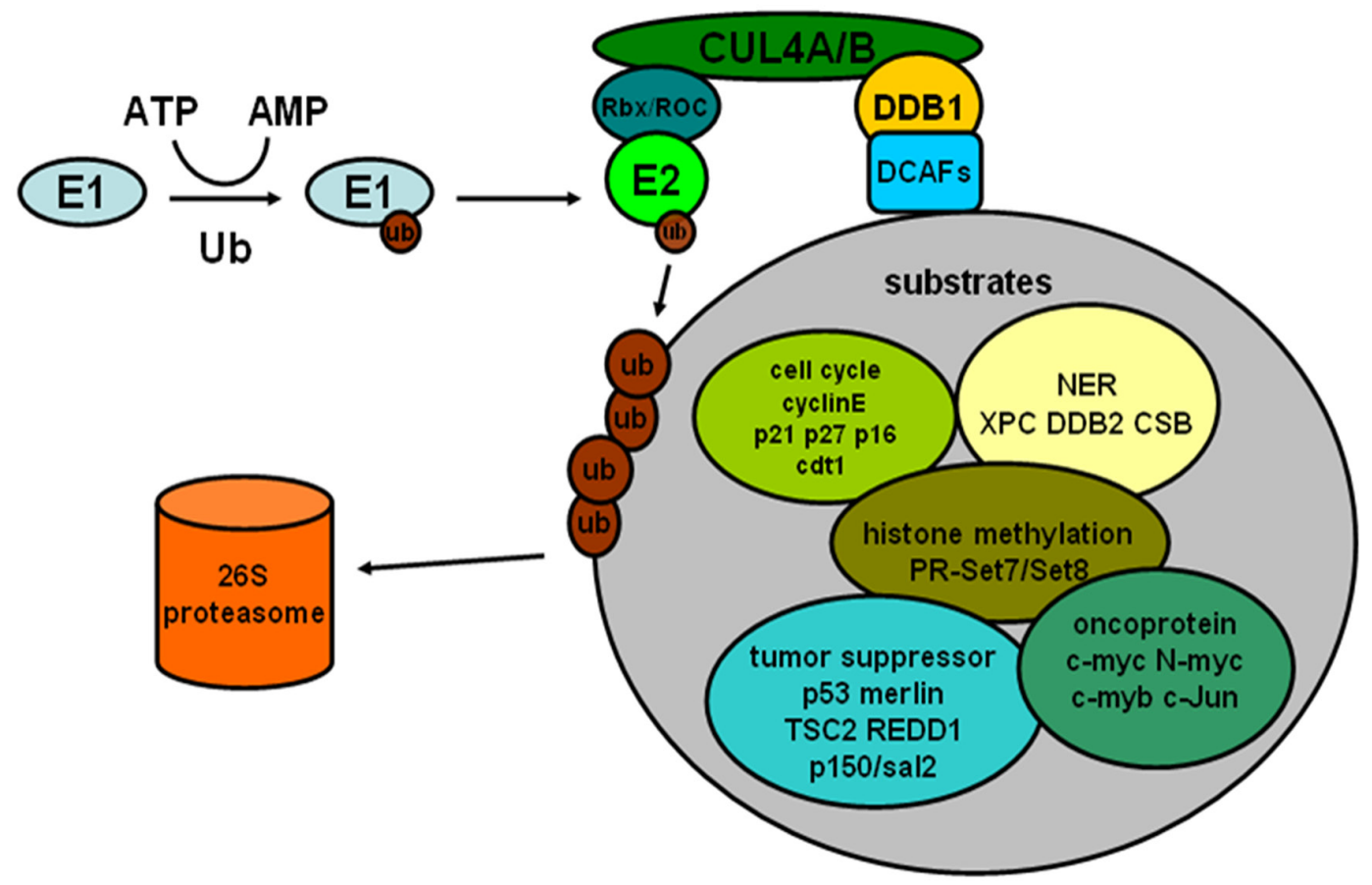

Figure 1: The process of ubiquitin-proteasome pathway and some substrates of CRL4 E3 ligases associated with cancer. 
components of CRL4 $4^{\mathrm{Cd} 2}$ inhibits $\mathrm{p} 12$, the subunit of DNA pol $\delta$, degradation in response to DNA damage, and p12 levels are reduced during the $\mathrm{S}$ phase under the control of CRL4 ${ }^{\text {Cdt2 }}$ during normal cell cycle progression [44-46]. The reduced expression of POLD4 encoding $\mathrm{p} 12$ protein has been found in lung cancer, which induces genomic instability [47].

Cdt1 is an important regulator of replication licensing and its regulation is critical for DNA replication once per cell cycle [48]. High level of Cdt1 contributes to aberrant replication and thus leads to malignant transformation [49]. So far, upregulation of Cdt1 has been found in many cancers such as colon and non-small-cell lung cancer. And Cdt1 overexpression could play a role in cancer development because its high level can occur early in premalignant diseases and participates in tumor development [50-52]. Cdt1 is degraded in response to different types of DNA lesions to ensure genomic stability. Cdt1 is present in G1 phase but at low levels after S phase by ubiquitin-mediated proteolysis. The work of Zhong et al. first provided proof that CRL4 complex degraded replication licensing factor $\mathrm{Cdt} 1$ during $\mathrm{S}$ phase to prevent re-replication [53]. Aberrant expression of CUL4 can be linked to unstable turnover of Cdt1 leading to DNA replication defects, aneuploidy and genomic instability and even cancer. In addition to CRL4, Cdt1 is also negatively regulated by geminin [54], $\mathrm{SCF}^{\mathrm{Skp} 2}$ complex [55] and APC [56]. The degradation of Cdt1 by CRL4 uses Cdt2 as substrate receptor, while the turnover of $\mathrm{Cdt} 2$ is also through ubiquitylation and then degradation. Studies found CRL1 $1^{\mathrm{FBXO11}}$ promoted the degradation of Cdt2 during $\mathrm{S}$ and $\mathrm{G}_{2} / \mathrm{M}$ phases.[57, 58] This suggests cross-talk between CRL1 and CRL4 ligase. CRL1 ${ }^{\text {FBXO11 }}$ degrades Cdt 2 leading to the restraint of CRL4 activity, for example the degradation of p21 and Set8. Another factors related to re-replication also include p21 and PR-Set7/Set8 histone H4K20 methyltransferase that accumulates during G2 and M phase. The both substrates of CRL4 complex are degraded in $\mathrm{S}$ phase to prevent re-replication [59].

\section{CRL4 AND NER}

Internal and external DNA-damaging agents induce DNA lesions, which constantly challenges DNA integrity. DNA lesions may lead to malignant transformation when such lesions are not repaired properly. Different DNA repair mechanisms remove different lesions and collectively safeguard genome stability. Nucleotide excision repair (NER) is a crucial pathway to detect and eliminate various lesions which mainly include two major lesions-cyclobutane pyrimidine dimers (CPD) and 6-4 pyrimidine-pyrimidone photoproducts (6-4PP) which are induced by UV irradiation [60]. NER includes two distinct subpathways: global genome NER (GGNER), which removes lesions in the whole genome DNA, and transcription-coupled NER (TC-NER), which repairs DNA lesions in the transcribed strand of active genes [61]. A number of reports have shown that impaired NER can cause many distinct disorders including xeroderma pigmentosum, neurodegeneration and developmental disorders such as Cockayne syndrome and trichothiodystrophy [62]. Among the above disorders, XP patients are sun-sensitive and generally show a greatly increased incidence of UV-induced skin cancers. Two major CRL4 E3 ligase substrate receptors in NER are the Cockayne-syndrome protein A (CSA) and the damage DNA binding protein 2 (DDB2) involved in TCR and GGR respectively [63]. NER factors involved in GGR mainly include XPA-RPA, XPC-HR23B, and damagespecific DNA-binding proteins consisting of DDB1 and DDB2 subunits. Following UV, DDB1-DDB2 complex immediately localizes to the site of DNA damage and then recruits XPC to DNA damage sites. XPC is then ubiquitinated by CRL4 ${ }^{\mathrm{DDB} 2}$ complex and subsequently deubiquitinated [64]. In Cul4a null MEFs, the levels of both DDB2 and XPC accumulate and dramatically enhance GGR activity. Furthermore, skin-specific Cul4a knockout mice increase resistance to UV-induced skin carcinogenesis because of elevated GGR [17]. Thus, inhibition of CRL4A ligase may provide a promising approach for UV-induced tumorigenesis. CSA and CSB are TCR factors, the mutation of which causes the Cockayne syndrome. Henning et al. reported that there was a physical interaction between CSA and CSB [65]. And CSA associates with CUL4A, which is involved in CRL4 E3 ligase [66]. Thus, CSB may be a substrate for CSA. In 2006, Groisman et al. showed that CUL4A ${ }^{\text {CSA }}$ E3 ligase activity up-regulation was accompanying with CSB ubiquitination and succeeding degradation after UV irradiation [67].

\section{CRL4 AND HISTONE METHYLATION}

Tumor development not only depends on the genetic factors, but also associates with epigenetic modification [68]. Now epigenetic modification mainly refers to the studies involving in DNA methylation and histone modifications. Abnormal epigenetic alterations are involved in cancer development and progression. Recently, histone modifications have been reported in various cancers, and some histone alterations are found to be associated with poor prognosis $[69,70]$. Histone modifications have abundant diversities which play important role in regulating a wide range of cellular processes such as transcription and genomic stability. Among them, histone methylation attaches more and more people's attention as a result of a host of evidence showing that there exists close relationship between dysfunction of histone methylation and tumor development [71]. Thus, the turnovers of factors associated with histone methylation would play important role in cancer. Higa et al. discovered CRL4 E3 ubiquitin ligase had critical effects 
on the regulation of histone methylation. They found that knockdown of CUL4 in HeLa cells resulted in reduced total level of H3K4me3, H3K9me3 and H3K27me3 [72]. And a recent study illustrated that CUL4A promoted $\mathrm{H} 3 \mathrm{~K} 4 \mathrm{me} 3$ at the promoter of ZEB1 and then led to transcriptional upregulation of ZEB1 expression in breast cancer cells, and knockdown of ZEB1 blocked CUL4Ainduced cell proliferation, EMT, tumorigenesis, and metastasis [14]. Thus, CUL4A can contribute to tumor development by the way of participating in histone methylation. Apart from CUL4A, latest work showed that CUL4B associated with Polycomb Repressive Complex 2 (PRC2) to play transcription repressive function through promoting H2AK119 monoubiquitination and H3K27 trimethylation at the promoter domain. The main target genes of CRL4B/PRC2 complex are p16 and PTEN, and CUL4B silencing results in increased expression of p16 and PTEN at both the transcriptional level and the protein level in KYSE410, HeLa, HEK293, MCF7 (human breast adenocarcinoma cell line), and U2OS (human osteosarcoma cell line). Moreover, CUL4B/PRC2 complex promotes cell proliferation and invasion because of downregulating its target genes [21].

Additionally, recent researches also found CRL4 could degrade enzymes involved in histone methylation to affect histone modification. The loss of the histone methyltransferase PR-Set7/Set activity results in defective DNA replication and genomic instability during $S$ phase [73]. This suggests that PR-Set7-mediated lysine methylation is a safeguarding factor for genome. PR-Set7 regulates the levels of $\mathrm{H} 4 \mathrm{~K} 20$ methylation, particularly for H4K20me1 and H4K20me3 [73]. And previous studies have shown that $\mathrm{H} 4-\mathrm{K} 20 \mathrm{me} 1$ is associated with chromatin condensation [74] and loss of H4-K20me3 is observed in many human cancers [75]. In addition, $\mathrm{Li}$, et al. found that SET8 participated in the Wnt signaling pathway [76], negatively regulated the function of p53 [77] and associated with TWIST activity, a master regulator of EMT [78], which suggested an interesting link between SET8 and carcinogenesis. Centore et al. suggested that Set8 was targeted by CRL4 ${ }^{\mathrm{Cd} 2}$ E3 ubiquitin ligase in a PCNA-dependent way for proteolysis in S phase and in response to DNA damage [59]. Furthermore at the same time, Abbas et al.[79] and Oda et al.[80] described similar points. Differences of the three groups are the exact time when PR-Set7 is degraded. Oda et al. found PR-Set7 is degraded during early G1 [80], while Abbas et al. and Centore et al. observed PR-Set7 is degraded specifically in $\mathrm{S}$ phase $[59,79]$. A previous study also reported $\mathrm{SCF} /$ Skp2 is an E3 ligase for PR-Set7 [81]. Thus, future studies should deal with the cross-talk between CRL4/Cdt2 and $\mathrm{SCF} / \mathrm{Skp} 2$ on the degradation of PR-Set7[82]. Given the regulation of PR-set7 on cell cycle, it will be interesting to explore whether PR-Set7 is a putative substrate for cellular transformation and contributes to tumor development. Furthermore, the regulation of CRL4 on the level of PR- set7 will provide proof to explore CRL4 in carcinogenesis.

\section{CRL4 AND TUMOR-RELATED SIGNALING PATHWAYS}

As is known, carcinogenesis is related to abnormal signaling pathways. At present, many studies have found that CUL4 levels associate with aberrant signal transduction. For example, misregulation of the Wnt pathway has been found in many tumors, including colon cancer [83], gastric cancer [84], lung couancer [85] and so on. Abnormal regulation of components involved in Wnt pathway associates with cancer development. $\beta$-catenin, as one important part of Wnt signaling, is the key event in transduction of the Wnt signal, upregulation of which is the causes of many cancers [86]. When the Wnt signaling is activated, $\beta$-catenin accumulates and then migrates into nucleus to form a complex with the Lef- $1 /$ Tcf- 1 in order to modulate the expression of target genes including some oncogenes such as c-myc $[87,88]$. In the absence of Wnt signals, $\beta$-catenin is targeted to degradation by ubiquitinproteasome pathway. In 1999, one paper showed that SCF complex used $\beta$-Trcp as substrate receptor to interact with $\beta$-catenin for its degradation. And serine phosphorylation of $\beta$-catenin is a prerequisite for its binding to $\beta$-Trcp [89]. Due to aberrant activation of the Wnt signaling pathway in tumor cells, $\beta$-catenin is no longer phosphorylated because of mutations in $\beta$-catenin itself or upstream elements that are critical for its phosphorylation, and thus escapes degradation. In 2007, another research found that CRL4B ligases could negatively regulate the expression of $\beta$-catenin [90]. Thus, the result supports the influence of CUL4B in Wnt regulation. However, so far there is no evidence to address the interplay between $\mathrm{SCF} / \beta$-Trcp and CUL4B on the degradation of $\beta$-catenin. Interestingly, Yuan et al. recently found CUL4B played a positively regulatory role in $\mathrm{Wnt} / \beta$-catenin signaling in hepatocellular carcinoma. They observed that in HCC tissues both CUL4B and $\beta$-catenin are overexpressed and the two are parallelly upregulated. In vitro, in CUL4B knockdown HCC cells, the level of total $\beta$-catenin protein was significantly reduced. With further experiments, they determined that CUL4B protected $\beta$-catenin from GSK3mediated degradation in HCC cells, leading to the upregulation of $\beta$-catenin [91]. In addition, the status of Wnt signaling pathway is also associated with some inhibitors. These inhibitors can prevent Wnt proteins from binding to their receptors or recruit some destruction complex to target $\beta$-catenin. The study found that CRL4B/PRC2 complexes promoted H2AK119me1 and H3K27me3 to repress expression of Wnt inhibitors, and thus activate Wnt signaling [91].

The mammalian target of rapamycin (mTOR), as a master regulator of cellular metabolism, proliferation, and survival, is a serine/threonine kinase forming two different and functionally distinct multiprotein 
complexes, mTORC1 and mTORC2 [92]. In many types of cancers, mTOR is aberrantly activated because of dysregulation of mTOR regulators or aberrant upstream signaling such as PI3K/AKT activation and PTEN loss. Recently, accumulating evidence suggests that CRL4 participates in the regulation of mTOR pathway by means of degradation or transcriptional repression of substrates related to mTOR. Merlin, a tumor suppressor and the protein product of the NF2 gene, plays important role in inhibition of cell proliferation and progression through the G1 phase of the cell cycle $[93,94]$. Loss of merlin can induce the development of multiple nervous system tumors including schwannomas and meningiomas [95]. In 2009, one research found that merlin was a novel negative regulator of $\mathrm{mTORC} 1$ and merlin deficiency resulted in the activation of $\mathrm{mTORC} 1$ signaling in human meningioma cells [96]. And the work of Li et al. proved that merlin could inhibit the activity of CUL4A ubiquitin ligase by recruiting associated substrate receptor $\mathrm{VprBP} /$ DCAF1 [97, 98]. But other report held opposite opinion that the CRL4 ${ }^{\mathrm{VprBP}}$ ubiquitin ligase targeted merlin for degradation [99]. Thus the issue of the functional relationship between merlin and CRL $4^{\mathrm{VprBP}}$ is an important topic for future studies. In addition to merlin, CRL4 can also upregulate the mTOR pathway through promoting ubiquitination and degradation of tuberous sclerosis 2 (TSC2), a tumor suppressor, that forms a complex with TSC1 which can inhibit the mTOR signaling in a RheBdependent manner [100, 101]. Moreover, researches indicated that TSC2 protein was identified for destruction by CRL4 E3 ubiquitin ligase via FBW5, a DDB1-binding WD40 protein. And overexpression of FBW5 or CUL4A promotes TSC2 protein degradation, while depletion of any department of FBW5, DDB1, or CUL4A/B stabilizes the turnover of TSC2 [101]. Lately, studies also found CUL4B repressed the expression of PTEN, the upregulator of mTOR [21].

Epidermal growth factor receptor (EGFR) has been found aberrant expression in many solid cancers [102-104]. Although ubiquitination pathway is the major mechanism involving in regulation of protein, the relationship between EGFR and CUL4 remains unclear. Lately, one study found in NSCLC cells CUL4A overexpression dramatically increased the level of EGFR transcript, while CUL4A silence markedly decreased the level of EGFR transcript [13]. Furthermore, CUL4A activates EGFR expression by the way of promoting H3K4 trimethylation. And they also found AKT, downstream target protein of EGFR, was increasingly phosphorylated due to CUL4A overexpression [13]. Thus, CUL4A may activated EGFR-AKT pathway, leading to NSCLC cells proliferation.

In addition to the above signal pathways, there are other signalings affected by CRL4 ligases. For example, CUL4B E3 ubiquitin ligase can degrade CSN5, while the latter has a crucial role in the regulation of BMP signaling by promoting the degradation of BMP inhibitor SMAD7 [105]. CRL4 can also regulate GRK5(G protein-coupled receptor kinase 5) which binds with $\mathrm{I} \kappa \mathrm{B}$ inhibiting the NF$\kappa \mathrm{B}-$ mediated transcription [106]. CUL4A overexpresses and collaborates with H-Ras in the transformation of human mammary epithelial cells, which is consistent with the high frequency of RAS pathway activation in basallike breast tumors [16].

\section{CRL4 AND ONCOPROTEINS}

The reason of why CRL4 ligase is concerned with cancer development and progression is its substrates including a variety of oncoproteins. For example, the $\mathrm{C}$-myc and $\mathrm{N}$-myc proto-oncogenes belong to the family of myc genes that include B-myc, L-myc, and s-myc. The overexpression of the both myc genes is frequently found in various human cancers, which include breast carcinoma [107], lung carcinoma [108], and rare cases of colon carcinoma [109]. A recent report found a novel pathway that targeted myc proteins for degradation and was suppressed in cancer cells. That is the CRL4 E3 ligase complex recruits substrate receptor TRCP4AP/TRUSS for myc degradation through the proteasome and TRUSS knockdown leads to an increased level of myc proteins [110]. So TRCP4AP/TRUSS plays a key role as a mycspecific receptor for the CRL4 ligase complex, controlling the turnover of myc protein. In addition, CRL4 ligase degrades other oncoproteins through specific substrate receptors. For example, CRL4 respectively recruits Fbxw5 [111] and COP1 [112] as substrate receptor to target c-Myb and c-Jun for ubiquitination.

\section{CRL4 AND CANCER THERAPY}

Because of the important role the ubiquitin system plays in cellular processes involved in cancer, development of drugs that modulate the activity of the system proves to be essential. Currently, bortezomib is the first and the only proteasome inhibitor approved by the US Food and Drug Administration for the treatment of multiple myeloma and cell lymphoma $[113,114]$. However, bortezomib generally inhibits proteasome function, in return there are many side effects. Thus, it is more valuable to develop a relatively specific means to modulate levels of important proteins. In ubiquitin-proteasome process, E3 ligases determine the substrate specificity, so targeting of specific E3s has the potential to selectively stabilize specific cellular proteins and would theoretically avoid side effects. MLN4924, a newly discovered small molecule inhibitor of NEDD8activating enzyme, inactivates CRL E3 ligases and consequently causes accumulation of CRLs substrates and suppresses tumor cell growth both in vitro and in vivo [115]. Thanks to selectively blocking degradation of a specific set of proteins regulated by CRL E3s, MLN4924induced cytotoxicity is less than that of targeting 
proteasomes by bortezomib. However, MLN4924 affects a broad range of substrates targeted by multiple CRLs E3 for degradation, which is similar to proteasome inhibition. Thus, the specific inhibition of individual CRLs may be more effective and provides a better therapeutic index than global inhibition via MLN4924.

Recent studies discussed above have shown that CRL4 plays essential roles in cancer. Overexpression of CUL4A/B has been demonstrated in many types of cancers $[9-12,21,22]$, and is associated with a poor prognosis of patient survival $[15,20]$. Moreover, knockdown of CUL4A/B inhibits the growth of cancer cells [16, 91, 116, 117], while CUL4A/B overexpression promotes malignant proliferation [14, 21, 118, 119]. Given these facts, CRL4 may be a potential target for cancer therapy.

Colon cancer is a common gastrointestinal cancer, and chemotherapy is a major treatment program for advanced cases. Irinotecan is one specific topoisomerase I (TOP1) inhibitor, but down-regulation of TOP1 has been found in some colon cancer cases, leading to reduced therapeutic effect of irinotecan. Researches found mutation of CUL4B decreased TOP1 ubiquitination and cells defective CUL4B exhibited sensitivity to camptothecin [120]. Thus, specific inhibitors of CUL4B could increase the level of TOP1 and consequently improve therapeutic effect of irinotecan on colon cancer. Pan et al. found ovarian cancer cells with overexpression of CRL4 were more sensitive to MLN4924 treatment than normal cells, such as ovarian surface epithelial cells and knockdown of CRL4 components in ovarian cancer cells mimicked the growth inhibition effects of MLN4924 [121]. Consequently, overexpression of CRL4 components is expected to be a useful biomarker for ovarian cancer and determines MLN4924 efficacy in cancer treatment. In addition, prostate cancer cells with high expression of CUL4A are sensitive to thalidomide, and apoptosis to thalidomide also depends on high level of CUL4A [122]. Screening of CUL4A level in prostate cancer patients benefits to determine whether some patients should accept therapy of thalidomide. Cereblon (CRBN) was first identified by Higgins et al. in patients with autosomal recessive nonsyndromic mental retardation [123]. Recently, studies found the level of CRBN in myeloma cells was associated with better treatment response in IMiDs (thalidomide, lenalidomide and pomalidomide) treatment $[124,125]$. Further studies found CRBN interacted with DDB1, CUL4 and ROC1 to form CRL4 ${ }^{\text {Cereblon }}$ E3 complex [126]. IMiDs directly bind Cereblon (CRBN), and promote substrates Ikaros and Aiolos to the CRL4 ${ }^{\text {Cereblon }}$ E3 complex for degradation, which is toxic to myeloma cells [127]. Overexpression of CDT2, one substrate receptor of CRL4, has been reported in many types of tumors such as breast [128], gastric [129], and ovarian carcinomas [121]. Silencing of CDT2 results in apoptotic death in cancer cells but not in non-transformed cells [130]. This suggests loss of CDT2 affects viability of cancer cells. Previous studies have found CRL4 ${ }^{\mathrm{CDT} 2}$ targets many substrates for destruction associated with cancer that include CDT1 [131], p21 [34] and CHK1 [132]. Consequently, down-modulation of CDT2 may be a promising approach to cancer therapy.

In addition, many works (discussed above) have found CRL4 participates in the regulations of signaling pathways associated with cancer. Specific inhibitors of CRL4 will change the status of these pathways, leading to get tumor inhibitory effects. For example, mTOR pathway has been found activated in a wide variety of diseases including cancer [92]. Thus, mTOR inhibitors such as temsirolimus [133] and Torin1 [134] may have a broad application in the treatment of cancer. Apart from this, modulating the turnover of mTOR-negative regulators may be an alternative approach of blocking mTOR pathway. Previous studies found TSC2 and REDD1, two mTOR-negative regulators, are degraded by CRL4 ${ }^{\mathrm{FBW} 5}$ ligase and CRL4 ${ }^{\beta-T r c p}$ ligase respectively $[101,135]$. Smallmolecule inhibitors of the CRL4 E3s are expected to cause their accumulation, leading to the inhibition of mTOR pathway.

Specific inhibitors of SCF E3s have been proved as the attractive anticancer targets [136]. Given both CRL4 E3s and SCF E3s belonging to the same family, so it is promising that specific inhibitors of CRL4 E3s as novel anticancer agents will be eventually discovered.

\section{CONCLUSIONS}

A significant number of recent works shed light on the biological functions of CRL4 E3 ligases that play a vital role in tumor development and progression. CRL4 ligases have been shown to degrade diverse substrates associated with a wide range of cellular processes that influence the course of cancer development and progression, including the cell cycle, genomic stability, transcriptional suppression, histone methylation and so on. Hence, given the roles of CRL4 ligases in tumorigenesis, CRL4-mediated ubiquitination pathways possess broad prospects in intervention and prevention of carcinogenesis. Nevertheless, even so many studies of cancer-relevant CRL4 ligases, there are still many controversies to be answered. For instance, more studies are apparently needed to further distinguish the functional distinction between CUL4A and CUL4B in cancer. Further works are essential to resolve the puzzling role of CRL4 ligases in the maintenance of genome stability. More molecules related to cancer need to be proved whether they are the substrates of CUL4. Additionally, drug specificity is also one urgent problem to resolve. Although many challenges are needed to represent the role of CRL4 ligases in tumor, a considerable wealth of information has been generated regarding the mechanisms of CRL4 ligases' biological function and their clinical implications in cancer. Moreover, more and more studies show that it will be a 
promising novel target for cancer therapy. Consequently, works on CRL4 ligases in cancer deserve more concerns in the future.

\section{ACKNOWLEDGMENTS}

This work was supported by the grants from National Natural Science Foundation of China (No. 81272221 ) and Tianjin Natural Science Foundation (No. 12JCYBJC16100) and $\mathrm{PhD}$ Research Foundation of Tianjin Medical University Cancer Institute and Hospital (B1309).

\section{CONFLICTS OF INTEREST}

There is no conflict of interest.

\section{REFERENCES}

1. Hochstrasser M. Ubiquitin-dependent protein degradation. Annual review of genetics. 1996; 30:405-439.

2. Petroski MD and Deshaies RJ. Function and regulation of cullin-RING ubiquitin ligases. Nature reviews Molecular cell biology. 2005; 6(1):9-20.

3. Hellmann $\mathrm{H}$ and Estelle M. Plant development: regulation by protein degradation. Science. 2002; 297(5582):793-797.

4. Duda DM, Borg LA, Scott DC, Hunt HW, Hammel M and Schulman BA. Structural insights into NEDD8 activation of cullin-RING ligases: conformational control of conjugation. Cell. 2008; 134(6):995-1006.

5. Lyapina S, Cope G, Shevchenko A, Serino G, Tsuge T, Zhou C, Wolf DA, Wei N, Shevchenko A and Deshaies RJ. Promotion of NEDD-CUL1 conjugate cleavage by COP9 signalosome. Science. 2001; 292(5520):1382-1385.

6. Lyapina SA, Correll CC, Kipreos ET and Deshaies RJ. Human CUL1 forms an evolutionarily conserved ubiquitin ligase complex (SCF) with SKP1 and an F-box protein. Proceedings of the National Academy of Sciences of the United States of America. 1998; 95(13):7451-7456.

7. He YJ, McCall CM, Hu J, Zeng Y and Xiong Y. DDB1 functions as a linker to recruit receptor WD40 proteins to CUL4-ROC1 ubiquitin ligases. Genes \& development. 2006; 20(21):2949-2954.

8. Lee J and Zhou P. DCAFs, the missing link of the CUL4DDB1 ubiquitin ligase. Molecular cell. 2007; 26(6):775780.

9. Melchor L, Saucedo-Cuevas LP, Munoz-Repeto I, Rodriguez-Pinilla SM, Honrado E, Campoverde A, Palacios J, Nathanson KL, Garcia MJ and Benitez J. Comprehensive characterization of the DNA amplification at 13q34 in human breast cancer reveals TFDP1 and CUL4A as likely candidate target genes. Breast cancer research. 2009; 11(6):R86.

10. Yasui K, Arii S, Zhao C, Imoto I, Ueda M, Nagai H, Emi
$\mathrm{M}$ and Inazawa J. TFDP1, CUL4A, and CDC16 identified as targets for amplification at 13q34 in hepatocellular carcinomas. Hepatology. 2002; 35(6):1476-1484.

11. Shinomiya T, Mori T, Ariyama Y, Sakabe T, Fukuda Y, Murakami Y, Nakamura Y and Inazawa J. Comparative genomic hybridization of squamous cell carcinoma of the esophagus: the possible involvement of the DPI gene in the 13q34 amplicon. Genes, chromosomes \& cancer. 1999; 24(4):337-344.

12. Hung MS, Mao JH, Xu Z, Yang CT, Yu JS, Harvard C, Lin YC, Bravo DT, Jablons DM and You L. Cul4A is an oncogene in malignant pleural mesothelioma. Journal of cellular and molecular medicine. 2011; 15(2):350-358.

13. Wang Y, Zhang P, Liu Z, Wang Q, Wen M, Wang Y, Yuan $\mathrm{H}$, Mao JH and Wei G. CUL4A overexpression enhances lung tumor growth and sensitizes lung cancer cells to erlotinib via transcriptional regulation of EGFR. Molecular cancer. 2014; 13:252.

14. Wang Y, Wen M, Kwon Y, Xu Y, Liu Y, Zhang P, He X, Wang Q, Huang Y, Jen KY, LaBarge MA, You L, Kogan SC, Gray JW, Mao JH and Wei G. CUL4A induces epithelial-mesenchymal transition and promotes cancer metastasis by regulating ZEB1 expression. Cancer research. 2014; 74(2):520-531.

15. Schindl M, Gnant M, Schoppmann SF, Horvat R and Birner P. Overexpression of the human homologue for Caenorhabditis elegans cul-4 gene is associated with poor outcome in node-negative breast cancer. Anticancer research. 2007; 27(2):949-952.

16. Saucedo-Cuevas LP, Ruppen I, Ximenez-Embun P, Domingo S, Gayarre J, Munoz J, Silva JM, Garcia MJ and Benitez J. CUL4A contributes to the biology of basallike breast tumors through modulation of cell growth and antitumor immune response. Oncotarget. 2014; 5(8):23302343.

17. Liu L, Lee S, Zhang J, Peters SB, Hannah J, Zhang Y, Yin Y, Koff A, Ma L and Zhou P. CUL4A abrogation augments DNA damage response and protection against skin carcinogenesis. Molecular cell. 2009; 34(4):451-460.

18. Li T, Hung MS, Wang Y, Mao JH, Tan JL, Jahan K, Roos $\mathrm{H}, \mathrm{Xu} \mathrm{Z}$, Jablons DM and You L. Transgenic mice for creinducible overexpression of the Cul4A gene. Genesis. 2011; 49(3):134-141.

19. Badura-Stronka M, Jamsheer A, Materna-Kiryluk A, Sowinska A, Kiryluk K, Budny B and Latos-Bielenska A. A novel nonsense mutation in CUL4B gene in three brothers with $\mathrm{X}$-linked mental retardation syndrome. Clinical genetics. 2010; 77(2):141-144.

20. Jiang T, Tang HM, Wu ZH, Chen J, Lu S, Zhou CZ, Yan DW and Peng ZH. Cullin 4B is a novel prognostic marker that correlates with colon cancer progression and pathogenesis. Medical oncology. 2013; 30(2):534.

21. Hu H, Yang Y, Ji Q, Zhao W, Jiang B, Liu R, Yuan J, Liu Q, Li X, Zou Y, Shao C, Shang Y, Wang Y and Gong 
Y. CRL4B catalyzes H2AK119 monoubiquitination and coordinates with PRC2 to promote tumorigenesis. Cancer cell. 2012; 22(6):781-795.

22. Yuan J, Jiang B, Zhang A, Qian Y, Tan H, Gao J, Shao $\mathrm{C}$ and Gong Y. Accelerated hepatocellular carcinoma development in CUL4B transgenic mice. Oncotarget. 2015; 6(17):15209-15221.

23. Warwick GP. Effect of the cell cycle on carcinogenesis. Federation proceedings. 1971; 30(6):1760-1765.

24. Stein GS, van Wijnen AJ, Stein JL, Lian JB, Montecino M, Zaidi SK and Braastad C. An architectural perspective of cell-cycle control at the G1/S phase cell-cycle transition. Journal of cellular physiology. 2006; 209(3):706-710.

25. Lopez-Beltran A, MacLennan GT and Montironi R. Cyclin $\mathrm{E}$ as molecular marker in the management of breast cancer: a review. Analytical and quantitative cytology and histology / the International Academy of Cytology [and] American Society of Cytology. 2006; 28(2):111-114.

26. Tahara E. Genetic alterations in human gastrointestinal cancers. The application to molecular diagnosis. Cancer. 1995; 75(6 Suppl):1410-1417.

27. Zou Y, Mi J, Cui J, Lu D, Zhang X, Guo C, Gao G, Liu Q, Chen B, Shao C and Gong Y. Characterization of nuclear localization signal in the $\mathrm{N}$ terminus of CUL4B and its essential role in cyclin E degradation and cell cycle progression. The Journal of biological chemistry. 2009; 284(48):33320-33332.

28. Higa LA, Yang X, Zheng J, Banks D, Wu M, Ghosh P, Sun $\mathrm{H}$ and Zhang $\mathrm{H}$. Involvement of CUL4 ubiquitin E3 ligases in regulating CDK inhibitors Dacapo/p27Kip1 and cyclin E degradation. Cell cycle. 2006; 5(1):71-77.

29. Brugarolas J, Chandrasekaran C, Gordon JI, Beach D, Jacks $\mathrm{T}$ and Hannon GJ. Radiation-induced cell cycle arrest compromised by p21 deficiency. Nature. 1995; 377(6549):552-557.

30. Viola MV, Fromowitz F, Oravez S, Deb S and Schlom J. ras Oncogene p21 expression is increased in premalignant lesions and high grade bladder carcinoma. The Journal of experimental medicine. 1985; 161(5):1213-1218.

31. Wang C, Chen Z, Ge Q, Hu J, Li F, Hu J, Xu H, Ye Z and Li LC. Up-regulation of p21(WAF1/CIP1) by miRNAs and its implications in bladder cancer cells. FEBS letters. 2014; 588(24):4654-4664.

32. Nakanishi M, Adami GR, Robetorye RS, Noda A, Venable SF, Dimitrov D, Pereira-Smith OM and Smith JR. Exit from G0 and entry into the cell cycle of cells expressing p21Sdi1 antisense RNA. Proceedings of the National Academy of Sciences of the United States of America. 1995; 92(10):4352-4356.

33. Bendjennat M, Boulaire J, Jascur T, Brickner H, Barbier V, Sarasin A, Fotedar A and Fotedar R. UV irradiation triggers ubiquitin-dependent degradation of $\mathrm{p} 21$ (WAF1) to promote DNA repair. Cell. 2003; 114(5):599-610.

34. Nishitani H, Shiomi Y, Iida H, Michishita M, Takami T and Tsurimoto T. CDK inhibitor p21 is degraded by a proliferating cell nuclear antigen-coupled Cul4-DDB1Cdt2 pathway during $\mathrm{S}$ phase and after UV irradiation. The Journal of biological chemistry. 2008; 283(43):2904529052.

35. Cang Y, Zhang J, Nicholas SA, Bastien J, Li B, Zhou P and Goff SP. Deletion of DDB1 in mouse brain and lens leads to p53-dependent elimination of proliferating cells. Cell. 2006; 127(5):929-940.

36. Liu L, Yin Y, Li Y, Prevedel L, Lacy EH, Ma L and Zhou P. Essential role of the CUL4B ubiquitin ligase in extra-embryonic tissue development during mouse embryogenesis. Cell research. 2012; 22(8):1258-1269.

37. Hall JR, Bereman MS, Nepomuceno AI, Thompson EA, Muddiman DC and Smart RC. C/EBPalpha regulates CRL4(Cdt2)-mediated degradation of p21 in response to UVB-induced DNA damage to control the G1/S checkpoint. Cell cycle. 2014; 13(22):3602-3610.

38. Chu IM, Hengst L and Slingerland JM. The Cdk inhibitor p27 in human cancer: prognostic potential and relevance to anticancer therapy. Nature reviews Cancer. 2008; 8(4):253267.

39. Li B, Jia N, Kapur R and Chun KT. Cul4A targets p27 for degradation and regulates proliferation, cell cycle exit, and differentiation during erythropoiesis. Blood. 2006; 107(11):4291-4299.

40. Bondar T, Kalinina A, Khair L, Kopanja D, Nag A, Bagchi $\mathrm{S}$ and Raychaudhuri P. Cul4A and DDB1 associate with Skp2 to target p27Kip1 for proteolysis involving the COP9 signalosome. Molecular and cellular biology. 2006; 26(7):2531-2539.

41. Kotake Y, Zeng Y and Xiong Y. DDB1-CUL4 and MLL1 mediate oncogene-induced p16INK4a activation. Cancer research. 2009; 69(5):1809-1814.

42. Kim WY and Sharpless NE. The regulation of INK4/ARF in cancer and aging. Cell. 2006; 127(2):265-275.

43. Collado M, Blasco MA and Serrano M. Cellular senescence in cancer and aging. Cell. 2007; 130(2):223-233.

44. Zhang S, Zhao H, Darzynkiewicz Z, Zhou P, Zhang Z, Lee EY and Lee MY. A novel function of CRL4(Cdt2): regulation of the subunit structure of DNA polymerase delta in response to DNA damage and during the $\mathrm{S}$ phase. The Journal of biological chemistry. 2013; 288(41):2955029561.

45. Lee MY, Zhang S, Lin SH, Wang X, Darzynkiewicz Z, Zhang $Z$ and Lee EY. The tail that wags the dog: p12, the smallest subunit of DNA polymerase delta, is degraded by ubiquitin ligases in response to DNA damage and during cell cycle progression. Cell cycle. 2014; 13(1):23-31.

46. Zhao H, Zhang S, Xu D, Lee MY, Zhang Z, Lee EY and Darzynkiewicz Z. Expression of the p12 subunit of human DNA polymerase delta (Pol delta), CDK inhibitor p21(WAF1), Cdt1, cyclin A, PCNA and Ki-67 in relation to DNA replication in individual cells. Cell cycle. 2014; 
13(22):3529-3540.

47. Huang QM, Tomida S, Masuda Y, Arima C, Cao K, Kasahara TA, Osada H, Yatabe Y, Akashi T, Kamiya K, Takahashi T and Suzuki M. Regulation of DNA polymerase POLD4 influences genomic instability in lung cancer. Cancer research. 2010; 70(21):8407-8416.

48. Caillat $\mathrm{C}$ and Perrakis A. Cdt1 and geminin in DNA replication initiation. Sub-cellular biochemistry. 2012; 62:71-87.

49. Petropoulou C, Kotantaki P, Karamitros D and Taraviras S. Cdt1 and Geminin in cancer: markers or triggers of malignant transformation? Frontiers in bioscience : a journal and virtual library. 2008; 13:4485-4494.

50. Bravou V, Nishitani H, Song SY, Taraviras S and Varakis J. Expression of the licensing factors, Cdt1 and Geminin, in human colon cancer. International journal of oncology. 2005; 27(6):1511-1518.

51. Karakaidos P, Taraviras S, Vassiliou LV, Zacharatos P, Kastrinakis NG, Kougiou D, Kouloukoussa M, Nishitani H, Papavassiliou AG, Lygerou Z and Gorgoulis VG. Overexpression of the replication licensing regulators hCdt 1 and hCde6 characterizes a subset of non-small-cell lung carcinomas: synergistic effect with mutant p53 on tumor growth and chromosomal instability-evidence of E2F-1 transcriptional control over hCdt1. The American journal of pathology. 2004; 165(4):1351-1365.

52. Liontos M, Koutsami M, Sideridou M, Evangelou K, Kletsas D, Levy B, Kotsinas A, Nahum O, Zoumpourlis V, Kouloukoussa M, Lygerou Z, Taraviras S, Kittas C, Bartkova J, Papavassiliou AG, Bartek J, et al. Deregulated overexpression of hCdt1 and hCdc6 promotes malignant behavior. Cancer research. 2007; 67(22):10899-10909.

53. Zhong W, Feng H, Santiago FE and Kipreos ET. CUL-4 ubiquitin ligase maintains genome stability by restraining DNA-replication licensing. Nature. 2003; 423(6942):885889.

54. Arias EE and Walter JC. Strength in numbers: preventing rereplication via multiple mechanisms in eukaryotic cells. Genes \& development. 2007; 21(5):497-518.

55. Kondo T, Kobayashi M, Tanaka J, Yokoyama A, Suzuki S, Kato N, Onozawa M, Chiba K, Hashino S, Imamura M, Minami Y, Minamino N and Asaka M. Rapid degradation of Cdt1 upon UV-induced DNA damage is mediated by SCFSkp2 complex. The Journal of biological chemistry. 2004; 279(26):27315-27319.

56. Sivaprasad U, Machida YJ and Dutta A. APC/C - the master controller of origin licensing? Cell division. 2007; 2:8.

57. Abbas T, Mueller AC, Shibata E, Keaton M, Rossi M and Dutta A. CRL1-FBXO11 promotes Cdt2 ubiquitylation and degradation and regulates Pr-Set7/Set8-mediated cellular migration. Molecular cell. 2013; 49(6):1147-1158.

58. Abbas T, Keaton M and Dutta A. Regulation of TGF-beta signaling, exit from the cell cycle, and cellular migration through cullin cross-regulation: SCF-FBXO11 turns off CRL4-Cdt2. Cell cycle. 2013; 12(14):2175-2182.

59. Centore RC, Havens CG, Manning AL, Li JM, Flynn RL, Tse A, Jin J, Dyson NJ, Walter JC and Zou L. CRL4(Cdt2)mediated destruction of the histone methyltransferase Set8 prevents premature chromatin compaction in $\mathrm{S}$ phase. Molecular cell. 2010; 40(1):22-33.

60. Mitchell DL, Adair GM and Nairn RS. Inhibition of transient gene expression in Chinese hamster ovary cells by triplet-sensitized UV-B irradiation of transfected DNA. Photochemistry and photobiology. 1989; 50(5):639-646.

61. Hanawalt PC and Spivak G. Transcription-coupled DNA repair: two decades of progress and surprises. Nature reviews Molecular cell biology. 2008; 9(12):958-970.

62. Cleaver JE. Cancer in xeroderma pigmentosum and related disorders of DNA repair. Nature reviews Cancer. 2005; 5(7):564-573.

63. Groisman R, Polanowska J, Kuraoka I, Sawada J, Saijo M, Drapkin R, Kisselev AF, Tanaka K and Nakatani Y. The ubiquitin ligase activity in the DDB2 and CSA complexes is differentially regulated by the COP9 signalosome in response to DNA damage. Cell. 2003; 113(3):357-367.

64. Sugasawa K, Okuda Y, Saijo M, Nishi R, Matsuda N, Chu G, Mori T, Iwai S, Tanaka K, Tanaka K and Hanaoka F. UV-induced ubiquitylation of XPC protein mediated by UV-DDB-ubiquitin ligase complex. Cell. 2005; 121(3):387400 .

65. Henning KA, Li L, Iyer N, McDaniel LD, Reagan MS, Legerski R, Schultz RA, Stefanini M, Lehmann AR, Mayne LV and Friedberg EC. The Cockayne syndrome group A gene encodes a WD repeat protein that interacts with CSB protein and a subunit of RNA polymerase II TFIIH. Cell. 1995; 82(4):555-564.

66. Saijo M. The role of Cockayne syndrome group A (CSA) protein in transcription-coupled nucleotide excision repair. Mechanisms of ageing and development. 2013; 134(56):196-201.

67. Groisman R, Kuraoka I, Chevallier O, Gaye N, Magnaldo T, Tanaka K, Kisselev AF, Harel-Bellan A and Nakatani Y. CSA-dependent degradation of CSB by the ubiquitinproteasome pathway establishes a link between complementation factors of the Cockayne syndrome. Genes \& development. 2006; 20(11):1429-1434.

68. Dawson MA and Kouzarides T. Cancer epigenetics: from mechanism to therapy. Cell. 2012; 150(1):12-27.

69. Waldmann $\mathrm{T}$ and Schneider $\mathrm{R}$. Targeting histone modifications - epigenetics in cancer. Current opinion in cell biology. 2013; 25(2):184-189.

70. Oh EJ, Yang WI, Cheong JW, Choi SE and Yoon SO. Diffuse large B-cell lymphoma with histone H3 trimethylation at lysine 27: another poor prognostic phenotype independent of $\mathrm{c}-\mathrm{Myc} / \mathrm{Bcl} 2$ coexpression. Human pathology. 2014; 45(10):2043-2050.

71. Pan H1, Luo XG, Guo S, Liu ZP. Histone methylation and 
its relationship with cancer. [Article in Chinese]. Sheng Li Ke Xue Jin Zhan. 2010 ;41(1):22-6.

72. Higa LA, Wu M, Ye T, Kobayashi R, Sun H and Zhang H. CUL4-DDB1 ubiquitin ligase interacts with multiple WD40-repeat proteins and regulates histone methylation. Nature cell biology. 2006; 8(11):1277-1283.

73. Tardat M, Murr R, Herceg Z, Sardet C and Julien E. PR-Set7-dependent lysine methylation ensures genome replication and stability through $\mathrm{S}$ phase. The Journal of cell biology. 2007; 179(7):1413-1426.

74. Trojer P, Li G, Sims RJ, 3rd, Vaquero A, Kalakonda N, Boccuni P, Lee D, Erdjument-Bromage H, Tempst P, Nimer SD, Wang YH and Reinberg D. L3MBTL1, a histone-methylation-dependent chromatin lock. Cell. 2007; 129(5):915-928.

75. Fraga MF, Ballestar E, Villar-Garea A, Boix-Chornet M, Espada J, Schotta G, Bonaldi T, Haydon C, Ropero S, Petrie K, Iyer NG, Perez-Rosado A, Calvo E, Lopez JA, Cano A, Calasanz MJ, et al. Loss of acetylation at Lys16 and trimethylation at Lys 20 of histone $\mathrm{H} 4$ is a common hallmark of human cancer. Nature genetics. 2005; 37(4):391-400.

76. Li Z, Nie F, Wang S and Li L. Histone H4 Lys 20 monomethylation by histone methylase SET8 mediates Wnt target gene activation. Proceedings of the National Academy of Sciences of the United States of America. 2011; 108(8):3116-3123.

77. Shi X, Kachirskaia I, Yamaguchi H, West LE, Wen H, Wang EW, Dutta S, Appella E and Gozani O. Modulation of p53 function by SET8-mediated methylation at lysine 382. Molecular cell. 2007; 27(4):636-646.

78. Yang F, Sun L, Li Q, Han X, Lei L, Zhang H and Shang Y. SET8 promotes epithelial-mesenchymal transition and confers TWIST dual transcriptional activities. The EMBO journal. 2012; 31(1):110-123.

79. Abbas T, Shibata E, Park J, Jha S, Karnani N and Dutta A. CRL4(Cdt2) regulates cell proliferation and histone gene expression by targeting PR-Set7/Set8 for degradation. Molecular cell. 2010; 40(1):9-21.

80. Oda H, Hubner MR, Beck DB, Vermeulen M, Hurwitz J, Spector DL and Reinberg D. Regulation of the histone H4 monomethylase PR-Set7 by CRL4(Cdt2)-mediated PCNAdependent degradation during DNA damage. Molecular cell. 2010; 40(3):364-376.

81. Yin Y, Yu VC, Zhu G and Chang DC. SET8 plays a role in controlling $\mathrm{G} 1 / \mathrm{S}$ transition by blocking lysine acetylation in histone through binding to $\mathrm{H} 4 \mathrm{~N}$-terminal tail. Cell cycle. 2008; 7(10):1423-1432.

82. Lee $\mathrm{J}$ and Zhou P. SETting the clock for histone H4 monomethylation. Molecular cell. 2010; 40(3):345-346.

83. Ashley N. Regulation of intestinal cancer stem cells. Cancer letters. 2013; 338(1):120-126.

84. Cai $\mathrm{C}$ and Zhu $\mathrm{X}$. The Wnt/beta-catenin pathway regulates self-renewal of cancer stem-like cells in human gastric cancer. Molecular medicine reports. 2012; 5(5):1191-1196.
85. Lundin A and Driscoll B. Lung cancer stem cells: progress and prospects. Cancer letters. 2013; 338(1):89-93.

86. Tian J, He H and Lei G. Wnt/beta-catenin pathway in bone cancers. Tumour biology : the journal of the International Society for Oncodevelopmental Biology and Medicine. 2014; 35(10):9439-9445.

87. Behrens J, von Kries JP, Kuhl M, Bruhn L, Wedlich D, Grosschedl R and Birchmeier W. Functional interaction of beta-catenin with the transcription factor LEF-1. Nature. 1996; 382(6592):638-642.

88. He TC, Sparks AB, Rago C, Hermeking H, Zawel L, da Costa LT, Morin PJ, Vogelstein B and Kinzler KW. Identification of c-MYC as a target of the APC pathway. Science. 1998; 281(5382):1509-1512.

89. Latres E, Chiaur DS and Pagano M. The human F box protein beta-Trcp associates with the Cul1/Skp1 complex and regulates the stability of beta-catenin. Oncogene. 1999; 18(4):849-854.

90. Tripathi R, Kota SK and Srinivas UK. Cullin4B/E3ubiquitin ligase negatively regulates beta-catenin. Journal of biosciences. 2007; 32(6):1133-1138.

91. Yuan J, Han B, Hu H, Qian Y, Liu Z, Wei Z, Liang X, Jiang B, Shao C and Gong Y. CUL4B activates Wnt/beta-catenin signalling in hepatocellular carcinoma by repressing Wnt antagonists. The Journal of pathology. 2015; 235(5):784795.

92. Zoncu R, Efeyan A and Sabatini DM. mTOR: from growth signal integration to cancer, diabetes and ageing. Nature reviews Molecular cell biology. 2011; 12(1):21-35.

93. Lopez-Lago MA, Okada T, Murillo MM, Socci N and Giancotti FG. Loss of the tumor suppressor gene NF2, encoding merlin, constitutively activates integrin-dependent mTORC1 signaling. Molecular and cellular biology. 2009; 29(15):4235-4249.

94. Lallemand D, Curto M, Saotome I, Giovannini M and McClatchey AI. NF2 deficiency promotes tumorigenesis and metastasis by destabilizing adherens junctions. Genes \& development. 2003; 17(9):1090-1100.

95. Gutmann DH. Molecular insights into neurofibromatosis 2. Neurobiology of disease. 1997; 3(4):247-261.

96. James MF, Han S, Polizzano C, Plotkin SR, Manning BD, Stemmer-Rachamimov AO, Gusella JF and Ramesh $\mathrm{V}$. NF2/merlin is a novel negative regulator of mTOR complex 1, and activation of mTORC1 is associated with meningioma and schwannoma growth. Molecular and cellular biology. 2009; 29(15):4250-4261.

97. Li W, You L, Cooper J, Schiavon G, Pepe-Caprio A, Zhou L, Ishii R, Giovannini M, Hanemann CO, Long SB, Erdjument-Bromage H, Zhou P, Tempst P and Giancotti FG. Merlin/NF2 suppresses tumorigenesis by inhibiting the E3 ubiquitin ligase CRL4(DCAF1) in the nucleus. Cell. 2010; 140(4):477-490.

98. Li W and Giancotti FG. Merlin's tumor suppression linked to inhibition of the E3 ubiquitin ligase CRL4 (DCAF1). 
Cell cycle. 2010; 9(22):4433-4436.

99. Huang $\mathrm{J}$ and Chen J. VprBP targets Merlin to the Roc1Cul4A-DDB1 E3 ligase complex for degradation. Oncogene. 2008; 27(29):4056-4064.

100. Inoki K, Corradetti MN and Guan KL. Dysregulation of the TSC-mTOR pathway in human disease. Nature genetics. 2005; 37(1):19-24.

101. Hu J, Zacharek S, He YJ, Lee H, Shumway S, Duronio RJ and Xiong Y. WD40 protein FBW5 promotes ubiquitination of tumor suppressor TSC2 by DDB1-CUL4-ROC1 ligase. Genes \& development. 2008; 22(7):866-871.

102. Sainsbury JR, Farndon JR, Needham GK, Malcolm AJ and Harris AL. Epidermal-growth-factor receptor status as predictor of early recurrence of and death from breast cancer. Lancet. 1987; 1(8547):1398-1402.

103. Veale D, Ashcroft T, Marsh C, Gibson GJ and Harris AL. Epidermal growth factor receptors in non-small cell lung cancer. British journal of cancer. 1987; 55(5):513-516.

104. Reifenberger G, Prior R, Deckert M and Wechsler W. Epidermal growth factor receptor expression and growth fraction in human tumours of the nervous system. Virchows Archiv A, Pathological anatomy and histopathology. 1989; 414(2):147-155.

105. He F, Lu D, Jiang B, Wang Y, Liu Q, Liu Q, Shao C, Li X and Gong Y. X-linked intellectual disability gene CUL4B targets Jab1/CSN5 for degradation and regulates bone morphogenetic protein signaling. Biochimica et biophysica acta. 2013; 1832(5):595-605.

106. Wu Z, Chen Y, Yang T, Gao Q, Yuan M and Ma L. Targeted ubiquitination and degradation of G-proteincoupled receptor kinase 5 by the DDB1-CUL4 ubiquitin ligase complex. PloS one. 2012; 7(8):e43997.

107. Mariani-Costantini R, Escot C, Theillet C, Gentile A, Merlo $\mathrm{G}$, Lidereau R and Callahan R. In situ c-myc expression and genomic status of the c-myc locus in infiltrating ductal carcinomas of the breast. Cancer research. 1988; 48(1):199205.

108. Little CD, Nau MM, Carney DN, Gazdar AF and Minna JD. Amplification and expression of the c-myc oncogene in human lung cancer cell lines. Nature. 1983; 306(5939):194196.

109. Augenlicht LH, Wadler S, Corner G, Richards C, Ryan L, Multani AS, Pathak S, Benson A, Haller D and Heerdt BG. Low-level c-myc amplification in human colonic carcinoma cell lines and tumors: a frequent, p53-independent mutation associated with improved outcome in a randomized multiinstitutional trial. Cancer research. 1997; 57(9):1769-1775.

110. Choi SH, Wright JB, Gerber SA and Cole MD. Myc protein is stabilized by suppression of a novel E3 ligase complex in cancer cells. Genes \& development. 2010; 24(12):12361241.

111. Kanei-Ishii C, Nomura T, Egoh A and Ishii S. Fbxw5 suppresses nuclear c-Myb activity via DDB1-Cul4-Rbx1 ligase-mediated sumoylation. Biochemical and biophysical research communications. 2012; 426(1):59-64.

112. Wertz IE, O'Rourke KM, Zhang Z, Dornan D, Arnott D, Deshaies RJ and Dixit VM. Human De-etiolated-1 regulates c-Jun by assembling a CUL4A ubiquitin ligase. Science. 2004; 303(5662):1371-1374.

113. Richardson PG, Barlogie B, Berenson J, Singhal S, Jagannath S, Irwin D, Rajkumar SV, Srkalovic G, Alsina M, Alexanian R, Siegel D, Orlowski RZ, Kuter D, Limentani SA, Lee S, Hideshima T, et al. A phase 2 study of bortezomib in relapsed, refractory myeloma. The New England journal of medicine. 2003; 348(26):2609-2617.

114. Fisher RI, Bernstein SH, Kahl BS, Djulbegovic B, Robertson MJ, de Vos S, Epner E, Krishnan A, Leonard JP, Lonial S, Stadtmauer EA, O'Connor OA, Shi H, Boral AL and Goy A. Multicenter phase II study of bortezomib in patients with relapsed or refractory mantle cell lymphoma. Journal of clinical oncology : official journal of the American Society of Clinical Oncology. 2006; 24(30):48674874.

115. Soucy TA, Smith PG, Milhollen MA, Berger AJ, Gavin JM, Adhikari S, Brownell JE, Burke KE, Cardin DP, Critchley S, Cullis CA, Doucette A, Garnsey JJ, Gaulin JL, Gershman RE, Lublinsky AR, et al. An inhibitor of NEDD8-activating enzyme as a new approach to treat cancer. Nature. 2009; 458(7239):732-736.

116. Song J, Zhang J and Shao J. Knockdown of CUL4A inhibits invasion and induces apoptosis in osteosarcoma cells. International journal of immunopathology and pharmacology. 2015; 28(2):263-269.

117. Dong J, Wang XQ, Yao JJ, Li G and Li XG. Decreased CUL4B expression inhibits malignant proliferation of glioma in vitro and in vivo. European review for medical and pharmacological sciences. 2015; 19(6):1013-1021.

118. Chen Z, Shen BL, Fu QG, Wang F, Tang YX, Hou CL and Chen L. CUL4B promotes proliferation and inhibits apoptosis of human osteosarcoma cells. Oncology reports. 2014; 32(5):2047-2053.

119. Yang Y, Liu R, Qiu R, Zheng Y, Huang W, Hu H, Ji Q, He H, Shang Y, Gong Y and Wang Y. CRL4B promotes tumorigenesis by coordinating with SUV39H1/HP1/ DNMT3A in DNA methylation-based epigenetic silencing. Oncogene. 2015; 34(1):104-118.

120. Kerzendorfer C, Whibley A, Carpenter G, Outwin E, Chiang SC, Turner G, Schwartz C, El-Khamisy S, Raymond FL and O'Driscoll M. Mutations in Cullin 4B result in a human syndrome associated with increased camptothecin-induced topoisomerase I-dependent DNA breaks. Human molecular genetics. 2010; 19(7):1324-1334.

121. Pan WW, Zhou JJ, Yu C, Xu Y, Guo LJ, Zhang HY, Zhou D, Song FZ and Fan HY. Ubiquitin E3 ligase CRL4(CDT2/ DCAF2) as a potential chemotherapeutic target for ovarian surface epithelial cancer. The Journal of biological chemistry. 2013; 288(41):29680-29691.

122. Ren S, Xu C, Cui Z, Yu Y, Xu W, Wang F, Lu J, Wei M, Lu 
X, Gao X, Liang Y, Mao JH and Sun Y. Oncogenic CUL4A determines the response to thalidomide treatment in prostate cancer. Journal of molecular medicine. 2012; 90(10):11211132.

123. Higgins JJ, Pucilowska J, Lombardi RQ and Rooney JP. A mutation in a novel ATP-dependent Lon protease gene in a kindred with mild mental retardation. Neurology. 2004; 63(10):1927-1931.

124. Huang SY, Lin CW, Lin HH, Yao M, Tang JL, Wu SJ, Chen YC, Lu HY, Hou HA, Chen CY, Chou WC, Tsay W, Chou SJ and Tien HF. Expression of cereblon protein assessed by immunohistochemicalstaining in myeloma cells is associated with superior response of thalidomide- and lenalidomide-based treatment, but not bortezomib-based treatment, in patients with multiple myeloma. Annals of hematology. 2014; 93(8):1371-1380.

125. Heintel D, Rocci A, Ludwig H, Bolomsky A, Caltagirone S, Schreder M, Pfeifer S, Gisslinger H, Zojer N, Jager U and Palumbo A. High expression of cereblon (CRBN) is associated with improved clinical response in patients with multiple myeloma treated with lenalidomide and dexamethasone. British journal of haematology. 2013; 161(5):695-700.

126. Ito $T$, Ando $H$ and Handa $H$. Teratogenic effects of thalidomide: molecular mechanisms. Cellular and molecular life sciences : CMLS. 2011; 68(9):1569-1579.

127. Kronke J, Udeshi ND, Narla A, Grauman P, Hurst SN, McConkey M, Svinkina T, Heckl D, Comer E, Li X, Ciarlo C, Hartman E, Munshi N, Schenone M, Schreiber SL, Carr SA, et al. Lenalidomide causes selective degradation of IKZF1 and IKZF3 in multiple myeloma cells. Science. 2014; 343(6168):301-305.

128. Ueki T, Nishidate T, Park JH, Lin ML, Shimo A, Hirata $\mathrm{K}$, Nakamura $\mathrm{Y}$ and Katagiri T. Involvement of elevated expression of multiple cell-cycle regulator, DTL/RAMP (denticleless/RA-regulated nuclear matrix associated protein), in the growth of breast cancer cells. Oncogene. 2008; 27(43):5672-5683.

129. Li J, Ng EK, Ng YP, Wong CY, Yu J, Jin H, Cheng VY, Go MY, Cheung PK, Ebert MP, Tong J, To KF, Chan FK, Sung JJ, Ip NY and Leung WK. Identification of retinoic acid-regulated nuclear matrix-associated protein as a novel regulator of gastric cancer. British journal of cancer. 2009; 101(4):691-698.

130. Olivero M, Dettori D, Arena S, Zecchin D, Lantelme E and Di Renzo MF. The stress phenotype makes cancer cells addicted to CDT2, a substrate receptor of the CRL4 ubiquitin ligase. Oncotarget. 2014; 5(15):5992-6002.

131. Jin J, Arias EE, Chen J, Harper JW and Walter JC. A family of diverse Cul4-Ddb1-interacting proteins includes Cdt2, which is required for $\mathrm{S}$ phase destruction of the replication factor Cdt1. Molecular cell. 2006; 23(5):709-721.

132. Huh J and Piwnica-Worms H. CRL4(CDT2) targets CHK1 for PCNA-independent destruction. Molecular and cellular biology. 2013; 33(2):213-226.
133. Rini BI. Temsirolimus, an inhibitor of mammalian target of rapamycin. Clinical cancer research : an official journal of the American Association for Cancer Research. 2008; 14(5):1286-1290.

134. Thoreen CC, Kang SA, Chang JW, Liu Q, Zhang J, Gao Y, Reichling LJ, Sim T, Sabatini DM and Gray NS. An ATP-competitive mammalian target of rapamycin inhibitor reveals rapamycin-resistant functions of mTORC1. The Journal of biological chemistry. 2009; 284(12):8023-8032.

135. Katiyar S, Liu E, Knutzen CA, Lang ES, Lombardo CR, Sankar S, Toth JI, Petroski MD, Ronai Z and Chiang GG. REDD1, an inhibitor of mTOR signalling, is regulated by the CUL4A-DDB1 ubiquitin ligase. EMBO reports. 2009; 10(8):866-872.

136. Skaar JR, Pagan JK and Pagano M. SCF ubiquitin ligasetargeted therapies. Nature reviews Drug discovery. 2014; 13(12):889-903. 